\title{
New approach for esthetic CAD/CAM crowns rehabilitation: case report
}

\begin{abstract}
Aesthetical treatment is a challenge to dental practice, especially by the subjectivity of an ideal aesthetical model, to achieve harmony between face and smile. To reestablish the harmony of the smile, aesthetical diagrams analyses are proposed previously to restorative interventions and computer-aided design and computer-aided manufacturing (CAD/CAM) chair-side system can help. Besides, the use of CAD/CAM chair-side system could reduce both chair and laboratory processing time. Therefore, the purpose of this study was to report the obtention of all-ceramic crowns, obtained in IPS Empress CAD Multi Block, to reestablish the aesthetical harmony of the anterior region. The $\mathrm{CAD} / \mathrm{CAM}$ use was the Cerec Sirona chairside CAD/CAM system and the mock-up, used to preview the aesthetic of the treatment, was made using prefabricated models belonging to the books "ANTERIORES" by Jan Hajto. The main difficulty of the case was to maintain harmony between the crowns of the two central and one lateral incisors and other lateral incisor.
\end{abstract}

Keywords: esthetics, dental, ceramics, computer aided design, computer aided manufacturing
Volume 7 Issue 4 - 2017

\section{Karla Zancope, Caio C sar Dias Resende, Lucas do Nascimento Tavares, Frederick Khalil Karam, $\mathrm{C}$ lio Jesus do Prado, FI vio Domingues das Neves \\ Department of Occlusion, Fixed Prostheses, and Dental} Materials, Federal University of Uberlandia, Brazil

Correspondence: Karla Zancopé, Department of Occlusion, Fixed Prosthodontics and Dental Materials, School of Dentistry, Federal University of Uberlândia, Av. Pará, I720, Bloco 4LA sala 4LA-42, Campus Umuarama, Uberlândia, Minas Gerais, Zip Code: 38405320, Brazil, Email karlazancope@gmail.com

Received: April 06, 2017 | Published: June 22, 2017

\section{Abbreviations: CAD, computer aided design; CAM, computer aided manufacturing.}

\section{Introduction}

Aesthetical treatment is a challenge to dental practice, especially by the subjectivity of an ideal aesthetical model, to achieve harmony between face and smile. ${ }^{1-3}$ To reestablish the harmony of the smile, aesthetical diagrams analyses are proposed previously to restorative interventions. These diagrams permit the definition of teeth positioning and proportion, their relationship with the new restorations, gingival tissue and lips. ${ }^{4}$ After the definition of these parameters, the choice of the ideal material should consider some factors, such as the rehabilitation area, space available, the aesthetical potential of each material, the translucency of the adjacent teeth, type of reminiscent and antagonist that occlude with the new restoration. ${ }^{5,6}$ Actually, with the Computer Aided Design/ Computer Aided Manufacturing (CAD/CAM) systems, the use of all-ceramic crowns $^{7}$ and the patients' expectations about the treatment has been increased. Saving time is one of the main advantages by using CAD/ CAM systems, accelerating the rehabilitation process on clinical routine. ${ }^{8,9}$ The Cerec Sirona chairside CAD/CAM system permits the creation of restorations, using a smile mock-up as a reference and a specific software tool (Biogeneric Copy). The virtual models are obtained by previously scanning the interest region and the mockup, which could be obtained using a wax-up model or prefabricated models, as demonstrating on this case report. ${ }^{8}$ The aim of this onesession case report was to demonstrate the obtention of all-ceramic crowns to reestablish the aesthetical harmony of the anterior region, using the Cerec Sirona chairside CAD/CAM system and prefabricated models as reference. This case report main challenge was to achieve natural aesthetic without surgical or restorative procedure on another dental element.

\section{Case presentation}

A 51-years old female patient, complained about the anterior aesthetical disharmony caused by different shape, color and texture between all anterior teeth (Figure 1). The patient presented all dental elements and good oral hygiene. Only both central incisors and the right lateral incisor presented restorative interventions; all other teeth were hygid or presented satisfactory direct restoration. The smile line was high and the anterior concave gingival arch was disharmonic. The patient did not consent to undergo to any surgical procedure or the use of provisional crowns, and would like to approve the rehabilitation before the procedures. The mock-up, used to preview the aesthetic of the treatment, was made using prefabricated models (Figure 2). ${ }^{10}$ To select the ideal prefabricated model, the length and the width of the left lateral incisor were measured and proportionally compared with the prefabricated models, in order to find one with similar characteristics. The model F2J was chosen and an impression was made using condensation-silicone impression material (Zetalabor, Zhermarck S.p.A, Badia Polesine, Rovigo, Italy) to copy the vestibular surface of the chosen prefabricated model, to obtain an index. With the aid of this silicon wall index, the vestibular surface was duplicated, to obtain laminated composite resin veneers (Filtek ${ }^{\mathrm{TM}}$ Z350 XT, 3M ESPE, Sumaré, SP, Brazil) (Figure 3). These veneers were provisionally cemented using resin flow (Opallis Flow, FGM Dental Products, Joinville, SC, Brazil) (Figure 4), so the patient could evaluate the shape and size of anterior teeth. After patient's approval, the virtual models were obtained, by scanning the interest region with Cerec Sirona Bluecam (Cerec; Sirona Dental Systems). The software tool "Biogeneric copy" (software InLab 4.0) was used, permitting the new restoration to be as similar as possible as the reference scanned before (Figure 5). The veneers were removed and the teeth were prepared for an all-ceramic crown. A standard set of diamond burs (KG Sorensen, Barueri, SP, Brazil) suitable for ceramic preparations 
was used. The preparation was free from undercuts, the angles were rounded and the walls were tapered 6 degrees to the occlusal surface. The margins were prepared with shoulders with rounded axiogingival line angles.11 Cervical margins of the preparations were exposed with gingival retractor cord number 000 and 0 (Ultrapack, Ultradent Products, Inc., South Jordan, Utah, EUA) (Figure 6) and the preparations were scanned (Figure 7). The interocclusal relationship and the opposing dentition were also scanned (Figure 8). The virtual casts were than mounted are distributed on the screen, and the operator could manipulate their X, Y and Z-axis. This step also permits the definition of the median line. Each preparation was die-cut and the finishing line was determined. The next step was to determine the insertion axis. To enhance the new restoration to be as similar as possible as the reference scanned before, each element vestibular surface was delimited and the software showed a mesh, similar to the reference, along to the models. Until this step, the operator could change the restorations' characteristics before the milling process. The last screen allowed the operator to change the position of the crown into the ceramic block. The IPS Empress CAD Multi Block (A2 C14 $\mathrm{L}$, Ivoclar Vivadent, Vita Zahnfabrik) is polychromatic as most teeth are, with a superior area with more translucent ceramic and an inferior area with less translucent ceramic (Figure 9). After 30 minutes, the three crowns were milled and ready to be tested and adjusted. Aesthetics, interproximal, cervical and interocclusal relationship were carefully evaluated and adjusted. The crowns were then glazed. To perform adhesive cementation, the crowns were treated by etching with hydrofluoric acid 10\% (Condac, FGM, Brazil) for 60 seconds and washed for 40 seconds. Silane (3M Spee, USA) was then applied for 1 minute. The crowns were individually cemented (Variolink, Ivoclair, Vivadent, Zahnfabrik). The gingival retractor cord number 000 (Ultrapack, Ultradent, EUA) was kept during the cementation process to avoid the excess material to extrude beyond the intended margins of the restoration. Periapical radiographs were realized after cementation process to evaluate the cementation line and the marginal fit (Figure 10). The patient related to be extremely satisfied with the anterior teeth aesthetic (Figure 11).

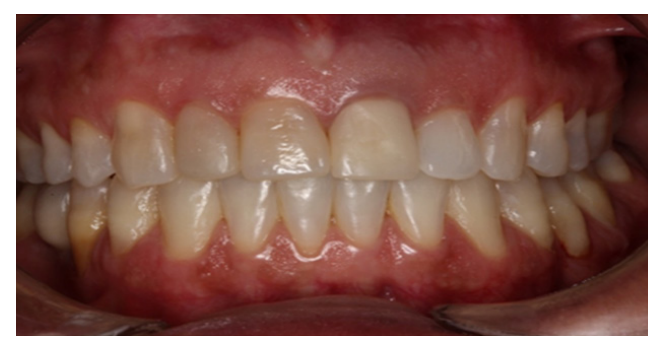

Figure I Initial appearance of patient.

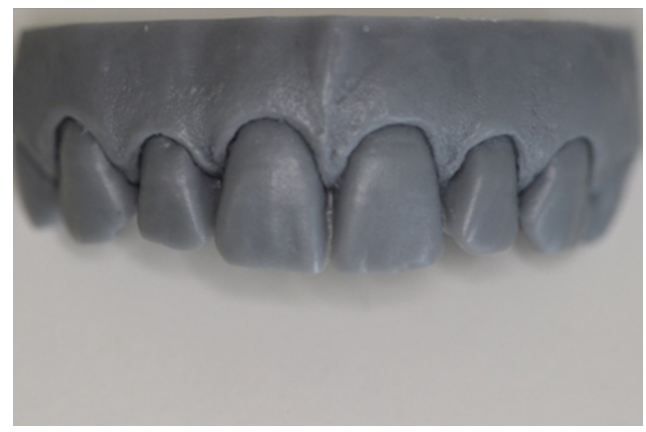

Figure 2 F2 J prefabricated model was selected using the length and width of the left lateral incisor with reference.

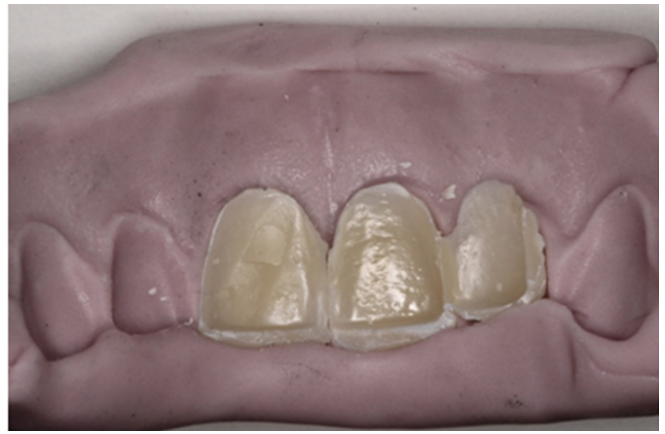

Figure 3 An index was made copying the vestibular surface of the chosen prefabricated model and laminated composite resin veneers was made.

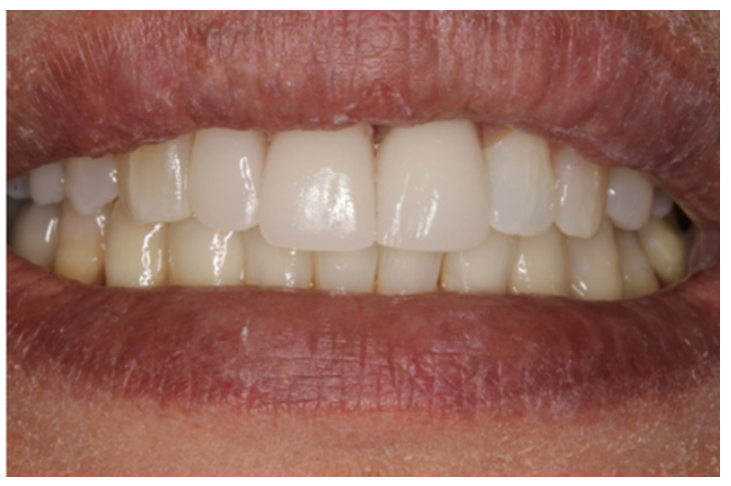

Figure 4 Appearance of patient's smile with veneers provisionally cemented using resin flow.

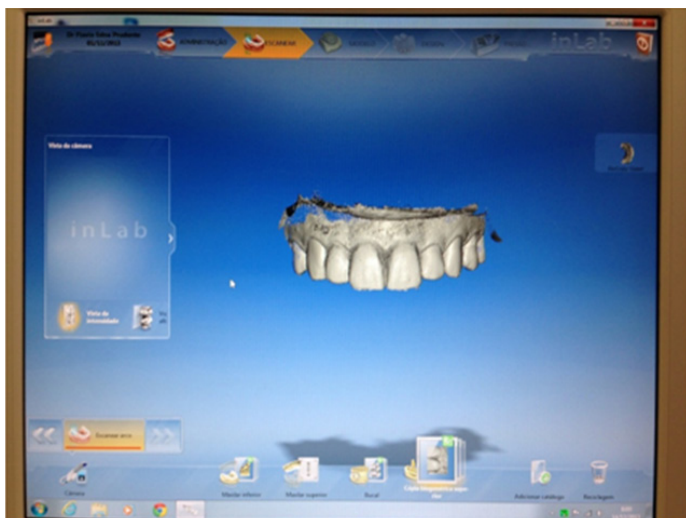

Figure 5 Biogeneric copy was used to scanner the veneers.

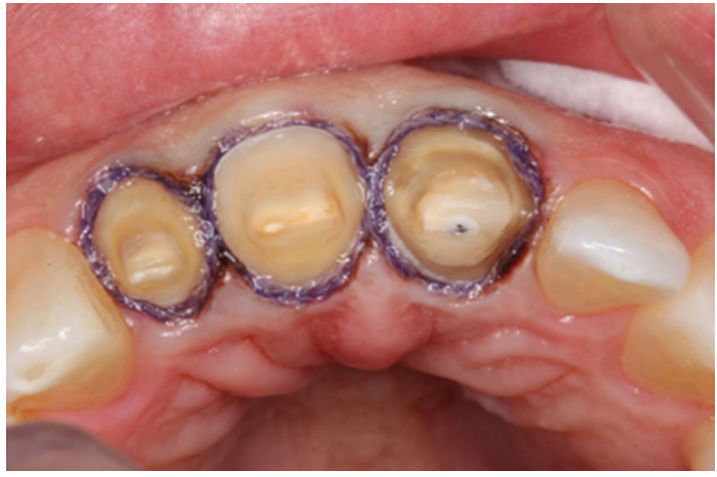

Figure 6 Gingival retractor cord number 000 was used to expose the cervical margin. 


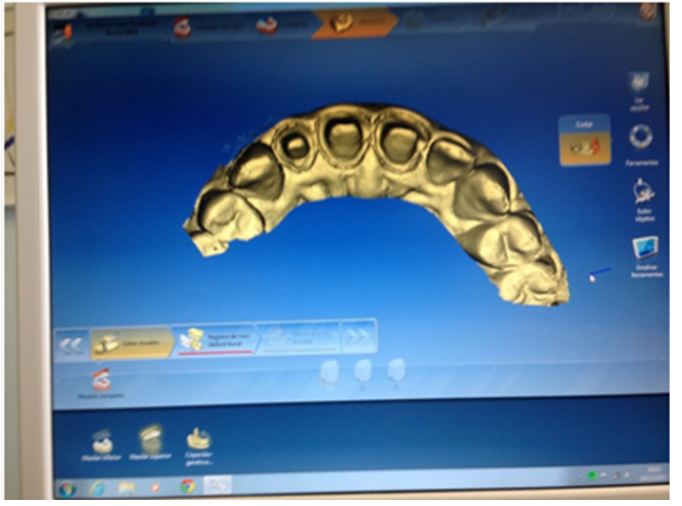

Figure 7 Virtual models of the prepared teeth.

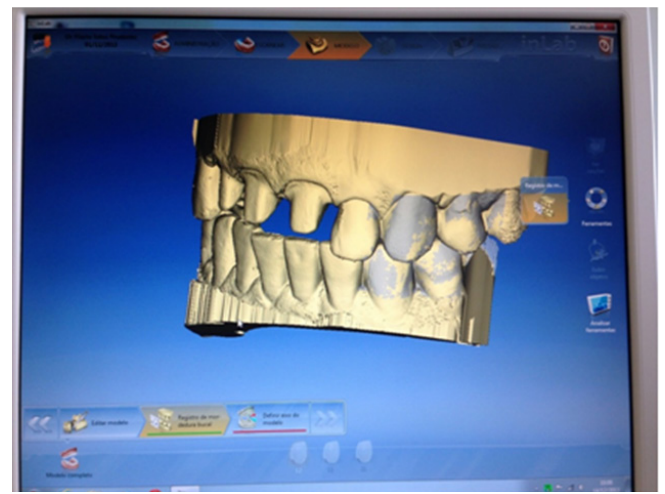

Figure 8 The interocclusal relationship was scanned and used with reference to definitely crowns.

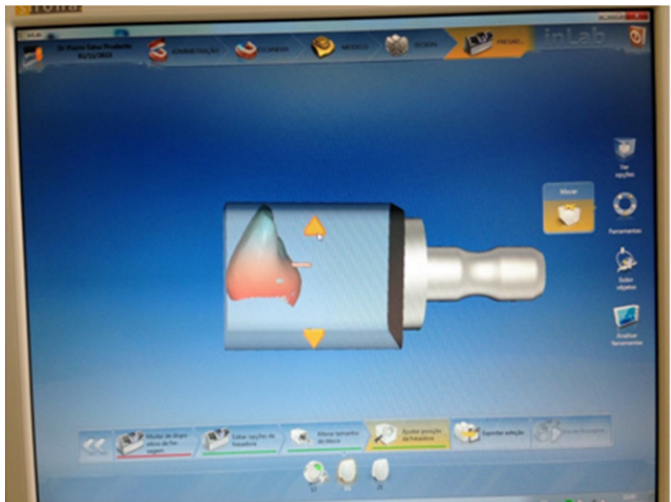

Figure 9 The selected IPS Empress CAD Multi Block presents different translucent area.

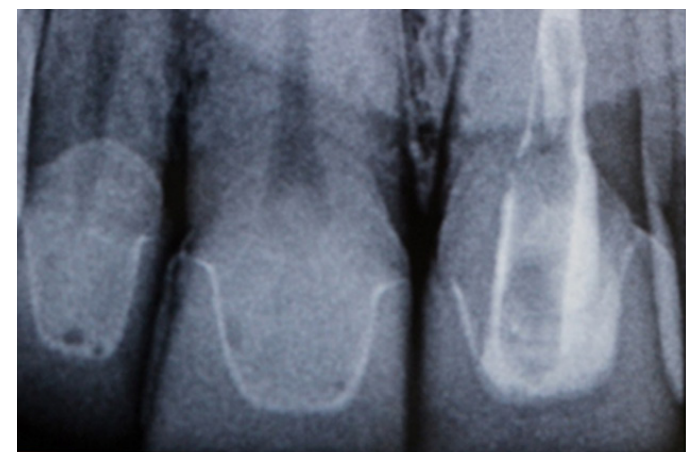

Figure 10 Periapical radiographs realized after cementation process to evaluate the cementation line.

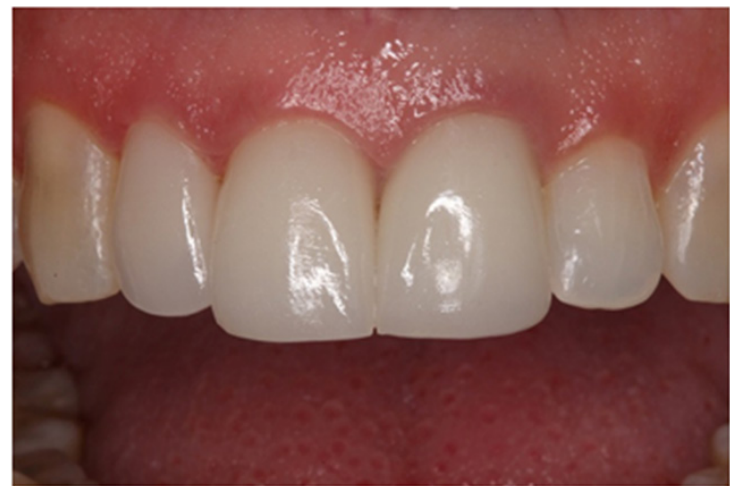

Figure II Final aspect of patient.

\section{Discussion}

There are several methods to obtain aesthetical harmony of anterior teeth. ${ }^{12,13}$ Before advances in physical properties of dental ceramics and resin adhesion to enamel and dentin, metal-ceramic crowns were the best option to aesthetic restorations, but it is still an established treatment applied on dental offices. The use of all-ceramic crowns obtained by CAD/CAM systems been increased. The CAD/ CAM chairside method can eliminates laboratory steps permitting to save clinical time, one of the patients' requirements. ${ }^{14,15}$ All-ceramic crows have excellent mechanical and optical properties, aesthetical appearance, biocompatibility and color stability. ${ }^{4-18}$ In this clinical case, the authors choice the block of leucite-reinforced glass-ceramic (IPS Empress CAD Multi Block, A2 C14 L, Ivoclar Vivadent) which was polychromatic, with a superior area with more translucent ceramic and an inferior area with less translucent ceramic. The patient wanted to solve the anterior aesthetical disharmony in a short time, without surgical intervention. The most difficult of this treatment is show for the patient the final result from treatment. According to the recent literature, the mock is effective way to increase the predictability of rehabilitation treatment, and there are three ways to get the mock-up. The first one, the operator could make a full-mouth impression and the prosthetist performs a wax-up ${ }^{13}$ with the desired result. This technique spends significant time and it is prosthetist dependent. In complex rehabilitations, the indirect wax-up is useful to analyze changes in vertical dimension of extensive cases. The second and third options are direct, therefore, second option allows the dentist to perform direct mock-up with composite resin restorations, ${ }^{19}$ but depends on dentists technical. Finally, there is a third possibility to apply the prefabricated models like a mock-up, ${ }^{10}$ as used in this clinical case, to ensure speed and quality to obtain the mock-up. It could be used for the aesthetic planning and production of front tooth provision or serve as a communication tool between dentist, patient and prosthetist that uses $\mathrm{CAD} / \mathrm{CAM}$ system. This third technique was used in this clinical case, but the first suggestion for the treatment plan is rehabilitate from a premolar to another, which is the limit of this technique possibility, because this not indicated for total reconstructions and reestablishment of the vertical dimension. It would still be necessary to perform a gingival surgery to improve gingival contour and increases the final cost of treatment. Thus, the patient signed an Informed Consent Form wanting to solve was her main complaint, which was rehabilitate only the teeth whit unsatisfactory composite resin restorations. Nowadays, there are five available ceramic blocks for CAD/CAM systems: feldsphatic, leucite-reinforced glass-ceramic, lithium disilicate, lithium silicate and zirconia ceramic. These ceramics differ specially by the aesthetical and mechanical characteristics. The zirconia ceramic 
demonstrates the highest fracture resistance of all ceramic types [20], however, the glass ceramics have better aesthetic properties. ${ }^{21-23}$ In this clinical case, the authors choose the block of leucite-reinforced glass-ceramic, with intermediate characteristics, adding resistance and aesthetic. Furthermore, the block (IPS Empress CAD Multi Block, A2 C14 L, Ivoclar Vivadent) was polychromatic, with a superior area with more translucent ceramic and an inferior area with less translucent ceramic. In this case, was utilized the CEREC CAD/CAM system has several tools to perform a crown design: Biogeneric Individual (the software designs the crown); Biogeneric Reference (the software copies and mirrors a pre-selected adjacent tooth) and Biogeneric Copy (the software copies pre-existing situations and duplicate the pre-op in the proposal); Which was performed in this clinical situation, with the scanning of prefabricated models, is possible to reproduce these aesthetics characteristics of the teeth for the mouth of the patient Is worth emphasizing that it was presented to the patient all the possibilities for treatment, thus allowing the patient choose whether to rehabilitate pre to premolar or only the three teeth that were her main complaint, thus enhancing the informed consent where the patient makes her choice based on treatment options provided by the dentist

\section{Funding}

None.

\section{Acknowledgments}

None.

\section{Conflicts of interest}

The author declares that there is no conflict of interest.

\section{References}

1. Langlois JH, Kalakanis L, Rubenstein AJ, et al. Maxims or myths of beauty? A meta-analytic and theoretical review. Psychol Bull. 2000;126(3):390-423.

2. Shaw WC, Richmond S, Kenealy PM, et al. A 20-year cohort study of health gain from orthodontic treatment: psychological outcome. Am J Orthod Dentofacial Orthop. 2007;132(2):146-157.

3. Chang CA, Fields HW, Beck FM, et al. Smile esthetics from patients' perspectives for faces of varying attractiveness. Am J Orthod Dentofacial Orthop. 2011;140(4):171-180.

4. Rigolin Ferreira FJ, Vasconcellos AA, Miranda ME, et al. Conservative restorations combined with gingival zenith contour technique. Quintessence Int. 2014;45(10):813-818.

5. Fehmer V, Mühlemann $\mathrm{S}$, Hämmerle $\mathrm{CH}$, et al. Criteria for the selection of restoration materials. Quintessence Int. 2014;45(9):723-730.

6. Edelhoff D, Sorensen JA. Light transmission through all- ceramic dependent on luting material. J Dent Res. 2002;16:231-234.

7. Dehghan M, Simon JF, Harrison J. Integrating the CEREC technology at UT College of Dentistry. J Tenn Dent Assoc. 2012;92(1):19-21.
8. Sannino G, Germano F, Arcuri L, et al. CEREC CAD/CAM Chairside System. Oral Implantol (Rome). 2015;7:57-70.

9. Drago CJ, Saldarriaga RL, Domagala D,et al.Volumetric determination of the amount of misfit in cad/cam and cast implant frameworks: a multicenter laboratory study. Int J Oral Maxillofac Implants. 2010;25(5):920-929.

10. Hajtó J. Anteriores-Naturally beautiful anterior teeth. 1st ed. Santos: São Paulo; 2008.

11. Goodacre CJ, Campagni WV, Aquilino SA. Tooth preparations for complete crowns: an art form based on scientific principles. J Prosthet Dent. 2001;85(4):363-376.

12. da Cunha LF, Mukai E, Hamerschmitt RM, et al. Fabrication of lithium silicate ceramic veneers with a CAD/CAM approach: A clinical report of cleidocranial dysplasia. J Prosthet Dent. 2015;113(5):355-359.

13. Soares PV, Spini PH, Carvalho VF, et al. Esthetic rehabilitation with laminated ceramic veneers reinforced by lithium disilicate. Quintessence Int. 2014;45(2):129-133.

14. Neves FD, Prado CJ, Prudente MS, et al. Micro-computed tomography evaluation of marginal fit of lithium disilicate crowns fabricated by using chairside CAD/CAM systems or the heat-pressing technique. J Prosthet Dent. 2014;112(5):1134-1140.

15. Das Neves FD, Do Prado CJ, Prudente MS, et al. Microcomputed tomography marginal fit evaluation of computer-aided design/computeraided manufacturing crowns with different methods of virtual model acquisition. Gen Dent. 2015;63(3):39-42.

16. De Andrade OS, Ferreira LA, Hirata R, et al. Esthetic and functiona rehabilitation of crowded mandibular anterior teeth using ceramic veneers: a case report. Quintessence Int. 2012;43(8):661-670.

17. Barnfather KD, Brunton PA. Restoration of the upper dental arch using Lava all-ceramic crown and bridgework. Br Dent J. 2007;202(12):731735.

18. Della Bona A, Mecholsky JJ, Anusavice KJ. Fracture behavior of lithia disilicate- and leucite-based ceramics. Dent Mater. 2004;20(10):956-962.

19. Gresnigt MM, Ozcan M. Fracture strength of direct versus indirect laminates with and without fiber application at the cementation interface. Dent Mater. 2007;23(8):927-933.

20. Zesewitz TF, Knauber AW, Northdurft FP. Fracture resistance of a selection of full-contour all-ceramic crowns: an in vitro study. Int $J$ Prosthodont. 2014;27(3):264-266.

21. Sorensen JA, Choi C, Fanuscu MI, et al. IPS Empress crown system: three-year clinical trial results. J Calif Dent Assoc. 1998;26(2):130-136.

22. Heintze SD, Rousson V. Fracture rates of IPS Empress all-ceramic crowns- a systematic review. Int J Prosthodont. 2010;23(2):129-133.

23. Makhija SK, Lawson NC, Gilbert GH, et al. National Dental PBRN Collaborative Group.. Dentist material selection for single-unit crowns: Findingsfrom the National Dental Practice-Based Research Network. $J$ Dent. 2016;55:40-47. 